\title{
Clinical Significance of Circulating Exosomal PD-L1 and Soluble PD-L1 in Nasal-type NK/T-cell Lymphoma Patients Receiving VIPD Containing Chemotherapy
}

\section{Jiwei Li}

Fudan University Shanghai Cancer Center https://orcid.org/0000-0003-3311-6512

\section{Ping Wei}

Fudan University shanghai cancer center

Ye Guo

Fudan University Shanghai Cancer Center

Di Shi

Fudan University Shanghai Cancer Center

\section{Bao-Hua Yu}

Fudan University Shanghai Cancer Center

\section{Yi-Fan Su}

Fudan University Shanghai Cancer Center

\section{Xiao-Qiu Li}

Fudan University Shanghai Cancer Center

Xiao-Yan Zhou ( $\nabla$ xyzhou100@163.com )

\section{Research}

Keywords: NK/T cell lymphoma, exosomal PD-L1, VIPD

Posted Date: August 2nd, 2020

DOI: https://doi.org/10.21203/rs.3.rs-51226/v1

License: (c) (i) This work is licensed under a Creative Commons Attribution 4.0 International License. Read Full License 


\section{Abstract}

Background: Several studies showed that circulating exosomal PD-L1 was associated with immunosuppression and prognosis in cancer patients. However, its prognostic value in extranodal NK/T cell lymphoma (ENKTCL) was poorly understood.

Methods: We retrospectively evaluated the prognostic value of pretreatment circulating PD-L1+ exosomes and soluble PD-L1 in the plasma of ENKTCL patients treated with VIPD-containing chemotherapy.

Results: A total of 107 ENKTCL patients, including 101 early stage and 6 advanced stage patients were enrolled in our study. Most patients were middle-aged and young male adults, with a male to female ratio of approximately 3.7:1. The 5year progression-free survival (PFS) and 5-year overall survival (OS) rates were $65.2 \%$ and $85.7 \%$ for the whole cohort, respectively. For early-stage patients, the L/P-VIPD group had better 5-year PFS than the VIPD group (73.6\% vs. 53.7\%, $P=0.031)$. Compared with the healthy individuals $(n=16)$, the patients with ENKTCL exhibited significantly elevated exoPD-L1 and SPD-L1 levels in the blood. Five-year PFS and OS rates were significantly lower in the high exoPD-L1 and SPD-L1 group than in the low exoPD-L1 and SPD-L1group. However, no correlation was found between circulating exoPDL1 and sPD-L1 levels ( $P=0.12, r=0.45)$.

Conclusions: Our results demonstrated that VIPD-containing chemotherapy combined with radiotherapy was a promising regimen in ENKTCL patients. Circulating exoPD-L1 and SPD-L1 levels were significantly elevated in ENKTCL and might be potential biomarkers for predicting the survival outcomes of ENKTCL patients.

\section{Background}

Extranodal NK/T cell lymphoma (ENKTCL) is a distinct type of non-Hodgkin lymphoma with a high degree of malignancy and frequent Epstein-Barr virus (EBV) infection[1]. The prognosis of ENKTCL with conventional anthracycline-based chemotherapy is poor, with a recurrence rate of $50 \%$ and a 5 -year OS rate lower than $50 \%[2,3]$. In the last decade, the application of L-asparaginase (L-asp) has provided insights into this malignant tumor type and achieved a 5-year OS rate of $64-74 \%$ in patients with early-stage disease [4-6]. Although the prognosis of ENKTCL has improved during the last decade, some patients still experience relapse within 3 years $[7,8]$.

Exosomes are nanovesicles with a diameter of 30-150 nm actively secreted by viable cells. Emerging evidence has demonstrated that lymphoma-derived exosomes play important roles in lymphomagenesis, lymphoma spread and drug resistance[9-11]. The programmed death protein 1(PD-1)/programmed death ligand 1 (PD-L1) pathway is one of the most critical mechanisms of tumor escape in lymphoma [12]. PD-L1 expressed in tumor cells can inhibit T cell proliferation and induce T cell exhaustion, contributing to immune evasion and cancer development. Recently, a group at the University of Pennsylvania found that PD-L1 present in the exosomal membrane could also mediate immune evasion and was a potential predictor of anti-PD-L1 treatment outcomes[13]. Subsequent studies have confirmed the role of exosomal PD-L1 (exoPD-L1) in immune escape in various cancers[14-16]. However, the exact significance and prognostic implications of plasma exoPD-L1 have not been determined in ENKTCL.

In this study, we explored the diagnostic and prognostic roles of exoPD-L1 in ENKTCL patients. As the predictive value of biological markers can be affected by primary treatment, we conducted this study in patients receiving VIPD-containing chemotherapy.

\section{Methods}

\section{Eligibility criteria}


This study evaluated the prognostic value of plasma exoPD-L1 and soluble PD-L1 (sPD-L1) levels in ENKTCL patients and was conducted at the Fudan University Shanghai Cancer Center. The inclusion criteria of the current study were as follows: 1) definite diagnosis of ENKTCL according to the World Health Organization (WHO) classification of lymphoid neoplasms; 2) the primary tumor site localized in the upper aerodigestive tract; 3) no prior treatment with detailed clinical information and follow-up data available; and 4) an Eastern Cooperative Oncology Group performance status (ECOG PS) score between 0-2. Patients with concomitant malignant tumors or severe organ dysfunction were excluded. This study was performed in accordance with the Declaration of Helsinki and approved by the Ethics Committees of the Fudan University Shanghai Cancer Center, and all the participants provided written informed consent.

\section{Evaluation and treatment}

The patients in our cohort were staged based on the Ann Arbor staging system. VIPD was administered in a three-week cycle and included etoposide $\left(75 \mathrm{mg} / \mathrm{m}^{2}\right)$, ifosfamide $\left(1,200 \mathrm{mg} / \mathrm{m}^{2}\right)$, cisplatin $\left(20 \mathrm{mg} / \mathrm{m}^{2}\right)$ and dexamethasone (40 mg) on days 1-4. P-VIPD consisted of intramuscular pegaspargase (Peg; $\left.2,500 \mathrm{IU} / \mathrm{m}^{2}\right)$ on day 1 and etoposide $\left(75 \mathrm{mg} / \mathrm{m}^{2}\right)$, ifosfamide $\left(1,200 \mathrm{mg} / \mathrm{m}^{2}\right)$, cisplatin $\left(20 \mathrm{mg} / \mathrm{m}^{2}\right)$ and dexamethasone $(40 \mathrm{mg})$ on days 2-4. L-VIPD included L-asp $\left(6,000 \mathrm{lU} / \mathrm{m}^{2}\right)$ on days $1-5$ and etoposide $\left(60 \mathrm{mg} / \mathrm{m}^{2}\right)$, ifosfamide $\left(1,200 \mathrm{mg} / \mathrm{m}^{2}\right)$, cisplatin $\left(20 \mathrm{mg} / \mathrm{m}^{2}\right)$ and dexamethasone (40 mg) on days 2-5; this treatment was repeated every 3 weeks. An intracutaneous test was required before the administration of L-ASP.

VIPD or L/P-VIPD combined with involved-field radiotherapy (IFRT) was delivered as the first-line treatment in early-stage patients. All advanced-stage patients received VIPD chemotherapy, and IFRT was a palliative or salvage therapy after failure of primary chemotherapy. Patient responses were evaluated according to the revised response criteria for malignant lymphoma[17]. All patients in our cohort underwent positron emission tomography-computed tomography (PET/CT) or magnetic resonance imaging (MRI) and/or computed tomography (CT) before treatment, after every two cycles of chemotherapy and after treatment.

\section{Exosome and peripheral blood mononuclear cell (PBMC) isolation from the blood}

Plasma samples of $500 \mu \mathrm{l}$ was thawed on ice. Exosomes was then isolated by using exoRNeasy Plasma Midi Kit (Qiagen, \#77044). PBMCs were isolated from whole blood with density gradient medium according to the manufacturer's instructions (Lymphoprep ${ }^{\text {TM }}$, STEMCELL Technologies, \#07851).

\section{Exosome characterization}

Exosomes purified from plasma were visualized using transmission electron microscopy (TEM) as described by Thery et al[18]. The size and concentration of exosomes were determined with the Flow NanoAnalyzer (NanoFCM Inc., Xiamen, China)[19]. In addition, the expression of exosomal markers such as TSG101 and ALIX was assessed by western blotting. Nanovesicles were lysed and separated by SDS/PAGE on 10\% gels. Proteins were transferred to PVDF membranes (Millipore, Boston, MA, USA) for western blot analysis. Then, the membranes were blocked with $5 \%$ bovine serum albumin for $1 \mathrm{~h}$ and incubated with antibodies against ALIX (124221, Proteintech), TSG101 (14497-1-AP, Proteintech), HSP90a/ $\beta$ (sc-13119, Santa Cruz), CD63 (ab193349, Abcam), PD-L1 (13684T, Cell Signaling Technology) and GAPDH (5174S, Cell Signaling Technology) overnight at $4{ }^{\circ} \mathrm{C}$, followed by washing with $1 \mathrm{x}$ TBS containing $0.1 \%$ Tween-20 (TSBT). The membranes were then incubated with an HRP-conjugated secondary antibody (Cell Signaling Technology) for $1 \mathrm{~h}$ at room temperature. After several washes with TBST, immunoreactive bands were visualized using 


\section{Detection of exOPD-L1 in the plasma based on a single-molecule array (Simoa)}

The Simoa HD-1 Analyzer is a digital immunoassay technology used for the detection of various proteins that has significantly higher sensitivity than the ELISA technique[20]. CD63 is one of the most important tetraspanins enriched on the exosomal surface and is considered a specific marker for exosomes[21]. Here, we used two markers, CD63 and PDL1, to detect PD-L1 expressed on exosomes in the plasma by Simoa.

Preparation of the Simoa Simoa homebrew kits for the the detection of extracellular vesicles (EVs) were prepared according to the manufacturer's guidelines. In brief, a capture anti-PD-L1 antibody was diluted to a concentration of $0.2 \mathrm{mg} / \mathrm{mL}$ with Bead Conjugation Buffer (Quanterix), and 1-ethyl-3-(3-dimethylaminopropyl) carbodiimide hydrochloride (EDC) (Thermo Fisher Scientific, Waltham, MA, USA) was used to activate paramagnetic carboxylated microparticles (Quanterix). Then, $3 \mu \mathrm{L}$ of biotin solution $(5.2 \mu \mathrm{g} / \mu \mathrm{l})$ was added to a detection antibody solution $(100 \mu \mathrm{L}, 1.0 \mathrm{mg} / \mathrm{mL})$ to start the biotinylation reaction. The recovered anti-CD63 antibody was adjusted to a concentration of $0.2 \mathrm{mg} / \mathrm{mL}$, and the beads were stored at $4{ }^{\circ} \mathrm{C}$. Finally, an assay for detecting PD-L1-positive exosomes via PD-L1-CD63 was developed.

Simoa setup Detection of PD-L1-positive exosomes was performed on a novel automated Simoa HD-1 Analyzer (Quanterix). Microscopic magnetic beads coated with an anti-PD-L1 capture antibody were diluted to 500,000/test, and an anti-CD63 detection antibody was adjusted to a working concentration of $0.3 \mu \mathrm{g} / \mathrm{mL}$. Streptavidin- $\beta$-galactosidase (SBG) was diluted to a working concentration of 150 pM with SBG Diluent (Quanterix). The detection process was a three-step protocol. First, $25 \mu \mathrm{L}$ of microscopic bead (coated with the anti-PD-L1 capture antibody) solution was incubated in a 100- $\mu \mathrm{L}$ sample for $45 \mathrm{~min}$, followed by three wash steps. Then, $100 \mu \mathrm{L}$ of anti-PD-L1 detection antibody was incubated with the microscopic beads for $5 \mathrm{~min}$ and $15 \mathrm{~s}$. Finally, $100 \mu \mathrm{L}$ of SBG was added and incubated for $5 \mathrm{~min}$ and $15 \mathrm{~s}$. An RGP substrate solution $(20 \mu \mathrm{L})$ was mixed with the microscopic beads and loaded into the Simoa disk array. The array was sealed with oil after loading, and the microscopic beads were imaged. Automatic analysis was performed with HD-1 Analyzer software (Quanterix), and the Simoa signal was present in AEB.

\section{Detection of SPD-L1 and exoPD-L1}

SPD-L1 in the blood was detected using a commercial ELISA kit (R\&D Systems, \# DB7H10). Serum samples were available for 96 ENKTCL patients and were measured in accordance with the manufacturer's instructions. For the detection of exoPD-L1, a total of $100 \mu$ of isolated exosomes was added to each well and then tested following the instructions. The minimum detectable level of SPD-L1 was $1.51 \mathrm{pg} / \mathrm{ml}$. Standards and all the samples were tested in duplicate.

\section{Statistical analysis}

Overall survival (OS) was defined as the time from the date of diagnosis to the day of last follow-up or death. Progression-free survival (PFS) was defined as the time from the day of diagnosis to the time of first progression, last follow-up or death. Survival analysis was performed using the Kaplan-Meier method, and the log-rank test was used to compare survival curves. Significant factors ( $P$ value less than 0.05 ) in univariate analyses were further examined by multivariate analysis with Cox regression. The prognostic cutoff points of plasma exoPD-L1, sPD-L1 and PET/CT 
SUVmax were determined by X-tile, and the most discriminant threshold for PFS was selected. Spearman correlation analysis was employed to identify correlations between variables.

\section{Results}

\section{Patient characteristics}

Table 1 summarizes patient clinical characteristics. A total of 107 patients with newly diagnosed nasal-type ENKTCL including 101 early-stage and 6 advanced-stage patients were enrolled in our study. Most patients in our cohort were middle-aged and young male adults, with a median age of 44 years (range, 17-76 years) and a male to female ratio of approximately 3.7:1. A majority of our patients had normal LDH levels $(n=91)$, low International Prognostic Index (IPI) scores $(\leq 1, n=97)$, low prognostic index of natural killer cell lymphoma (PINK) scores $(\leq 1, n=96)$ and early-stage disease $(n=96)$. B symptoms were present in over half of the patients $(n=55)$ in our cohort. The primary tumor sites included the nasal cavity $(n=103)$ and nasopharynx $(n=4)$. Pretreatment PET/CT was performed in 51 patients, with a median SUVmax value of 9.7 (range 3.2-25.1). Ki-67 was highly expressed in most patients, with a wide range of distribution from $5-99 \%$ and a median value of $60 \%$. For early stage patients, there is no obvious difference between the baseline clinical characteristics for VIPD group and L/P-VIPD group. 
Table 1

Patient characteristics.

\begin{tabular}{|c|c|c|c|c|}
\hline \multirow[t]{3}{*}{ Characteristics } & \multirow[t]{3}{*}{ Patient number $(n=107)$} & \multicolumn{2}{|c|}{ Early stage nasal type $\operatorname{ENKTCL}(n=101)$} & \multirow{3}{*}{$P$ value } \\
\hline & & VIPD & L/P-VIPD group $(n=67)$ & \\
\hline & & group $(n=34)$ & ggroupgroup & \\
\hline Gender & & & & 0.146 \\
\hline Male & $84(78.5)$ & 29 & 48 & \\
\hline Female & $23(21.5)$ & 5 & 19 & \\
\hline Age (years) & & & & 1.000 \\
\hline$>60$ & $11(10.3)$ & 3 & 6 & \\
\hline$\leq 60$ & $96(89.7)$ & 31 & 61 & \\
\hline Median (years) & 57.0 & 43.5 & 43.0 & \\
\hline ECOG PS & & & & 1.000 \\
\hline $0-1$ & 106(99.1) & 34 & 66 & \\
\hline $2-4$ & $1(0.9)$ & 0 & 1 & \\
\hline B symptoms & & & & 0.404 \\
\hline Yes & $55(51.4)$ & 15 & 36 & \\
\hline No & $52(48.6)$ & 19 & 31 & \\
\hline IPI score & & & & 0.685 \\
\hline$\leq 1$ & 97(90.7) & 31 & 63 & \\
\hline$>1$ & 10(9.3) & 3 & 4 & \\
\hline LDH level & & & & 0.066 \\
\hline Elevated & $16(15.0)$ & 8 & 6 & \\
\hline Normal & $91(85.0)$ & 26 & 61 & \\
\hline Primary sites & & & & 0.549 \\
\hline Nasal cavity & 102(95.3) & 34 & 65 & \\
\hline nasopharynx & $5(4.7)$ & 0 & 2 & \\
\hline PINK & & & & 0.115 \\
\hline $0-1$ & $96(89.7)$ & 29 & 64 & \\
\hline$\geq 2$ & $11(10.3)$ & 5 & 3 & \\
\hline Ki- $67 \geq 60 \%$ & $56(61.0)$ & 14 & 39 & 0.140 \\
\hline EBER + & 99(92.5) & 31 & 65 & 0.332 \\
\hline
\end{tabular}




\section{Evaluation of efficacy and survival outcomes}

Of the 101 patients with early-stage ENKTCL, VIPD was used to treat 34 patients, and L/P-VIPD was used to treat 67 patients. All the advanced-stage patients $(n=6)$ received VIPD chemotherapy. The complete response $(C R)$ rate and objective response rate (ORR) for the whole cohort after treatment were $76.2 \%$ and $95.2 \%$, respectively, whereas three patients developed progressive disease (PD). Thirty patients $(30.8 \%)$ relapsed $(n=30,28.0 \%)$ or developed PD $(n=3$, $2.8 \%)$ during the follow-up period.

The median follow-up time was 65.0 months (range, 2-119 months) in our study, with 5-year PFS and 5-year OS rates of $65.2 \%$ and $85.7 \%$, respectively (Fig. 1A-1B). Compared with VIPD, L/P-VIPD significantly improved the 5-year PFS rate in early-stage patients $(73.6 \%$ vs. $53.7 \%, P=0.031)$. However, no difference in the OS rate was found between the two groups (5-year OS $88.7 \%$ vs. $82.5 \%, P=0.604$ ) (Fig. 1C-1D).

Patients with an SUVmax $\geq 15.4(\mathrm{n}=10)$ on pretreatment PET/CT had worse 5-year PFS $(35.0 \%$ vs. $79.3 \%, P=0.002)$ and OS $(64.0 \%$ vs. $88.7 \%, P=0.038)$ than those with an SUVmax $<15.4(n=41)$ (Fig. 1E-1F). In addition, the 5-year PFS ( $49.1 \%$ vs. $66.7 \%, P=0.275)$ and OS rates $(60.6 \%$ vs. $88.1 \%, P=0.030)$ in the high-risk group (PINK $\geq 2)$ were inferior to those in the low-risk group (PINK $\leq 1)($ Fig. 1G-1H).

\section{Pretreatment exoPD-L1 levels and their correlations with clinical features}

Exosomes from ENKTCL patient were isolated by exoRNeasy Plasma Midi Kit. As shown in Fig. 2A, the TEM image revealed that exosomes were 30-100 nm intact vesicles. Flow NanoAnalyzer showed that the isolated exosomes were approximately $50-250 \mathrm{~nm}$ in diameter, with a median value of around $70 \mathrm{~nm}$ (Fig. 2B). Western blotting demonstrated that some specific biomarkers for exosomes, such as TSG101, ALIX, Hsp90a/ $\beta$ and CD63, were enriched in the isolated exosomes (Fig. 2C). Western blot analysis established that plasma exoPD-L1 level was significantly higher in ENKTCL patients than in healthy subjects (Fig. 2D). In accordance with the above result, the exoPD-L1 level detected by simoa was also obviously higher in the ENKTCL patients (Fig. 2E).

To validate the specificity of simoa, the plasma exoPD-L1 level was tested by both simoa and commercial ELISA method. A relatively good linear relationship between the simoa signal and the exoPD-L1 concentration detected by ELISA was obtained (Fig. 2F). Therefore, 99 ENKTCL patients and 16 healthy subjects with available plasma was further tested by simoa. In our study, we found that pretreatment plasma exoPD-L1 levels were significantly higher in our patients than in healthy subjects $(\mathrm{P}<0.001)$ (Fig. $2 \mathrm{G})$. Receiver operating characteristic curve $(\mathrm{ROC})$ showed that plasma exoPD-L1 provides an excellent diagnosis accuracy $(A U C=0.9968)$ to differentiate the ENKTCL patient $(n=99)$ and healthy control groups $(n=16)($ Fig. $2 H)$. The optimal prognostic cutoff point for the pretreatment plasma exoPD-L1 level measured by simoa was 1.2 (around 43.0 pg/ml) (X-tile, Supplementary Fig. 1) and our cohort was classified into two groups based on this value. To investigate the correlation between plasma exOPD-L1 and prognostic factors, pretreatment exoPD-L1 levels were compared based on the clinical parameters of our cohort (Table 2). Compared with those in the low plasma exoPDL1 group (simoa signal < 1.2), the patients in the high plasma exoPD-L1 group were more likely to have a high SUVmax level and a higher recurrence rate (Table 2). However, no correlations were observed between the plasma exoPD-L1 level and age, sex, disease stage, the B symptom status, the LDH level, the IPI score or the PINK score. The pretreatment plasma exoPD-L1 levels of patients with a higher SUVmax were significantly higher than those of patients with a lower SUVmax level $(P=0.003)$ (Fig. 2I). 
Table 2

Circulating exoPD-L1 and SPD-L1 predicted poor prognosis in ENKTCL patients.

\begin{tabular}{|c|c|c|c|c|c|c|c|c|}
\hline \multirow[t]{2}{*}{ Characteristics } & \multicolumn{4}{|c|}{ ENKTCL, nasal type } & \multicolumn{4}{|c|}{ ENKTCL, nasal type } \\
\hline & Total & $\begin{array}{l}\text { High exoPD- } \\
\text { L1 group }\end{array}$ & $\begin{array}{l}\text { Low exoPD- } \\
\text { L1 group }\end{array}$ & $\begin{array}{l}\text { P- } \\
\text { Value }\end{array}$ & Total & $\begin{array}{l}\text { High sPD- } \\
\text { L1 group }\end{array}$ & $\begin{array}{l}\text { Low sPD- } \\
\text { L1 group }\end{array}$ & $\begin{array}{l}\mathrm{P} \text { - } \\
\text { value }\end{array}$ \\
\hline $\begin{array}{l}\text { Patient } \\
\text { number }\end{array}$ & 99 & 11 & 88 & & 96 & 21 & 75 & \\
\hline Gender & & & & 0.696 & & & & 0.183 \\
\hline Male & 78 & $8(10.3)$ & 70(89.7) & & 73 & $18(24.7)$ & $55(75.3)$ & \\
\hline Female & 21 & $3(14.3)$ & 18(85.7) & & 23 & $3(13.0)$ & $20(87.0)$ & \\
\hline Age (years) & & & & 1.000 & & & & 0.163 \\
\hline$>60$ & 11 & $1(9.1)$ & 10(90.9) & & 7 & $3(42.9)$ & $4(57.1)$ & \\
\hline$\leq 60$ & 88 & 10(11.4) & 78(88.6) & & 89 & $18(20.2)$ & $71(79.8)$ & \\
\hline Stage & & & & 0.516 & & & & 0.006 \\
\hline$H-I I$ & 93 & 10(10.8) & 83(89.2) & & 90 & 17(18.9) & 73(81.1) & \\
\hline III-IV & 6 & $1(16.7)$ & $5(83.7)$ & & 6 & $4(66.7)$ & 2(33.3) & \\
\hline B symptoms & & & & 0.749 & & & & 0.006 \\
\hline Yes & 54 & $7(13.0)$ & $47(87.0)$ & & 50 & $16(32.0)$ & $34(68.0)$ & \\
\hline No & 45 & $4(8.9)$ & 41(91.1) & & 46 & $5(10.9)$ & $41(89.1)$ & \\
\hline LDH level & & & & 1.000 & & & & <. 001 \\
\hline Elevated & 16 & 1(6.3) & 15(93.7) & & 14 & $10(71.4)$ & $4(28.6)$ & \\
\hline Normal & 93 & 10(10.8) & 83(89.2) & & 82 & 11(13.4) & $71(86.6)$ & \\
\hline IPI & & & & 0.306 & & & & <. 001 \\
\hline $0-1$ & 89 & $9(10.1)$ & $80(89.9)$ & & 87 & $14(16.1)$ & 73(83.9) & \\
\hline$\geq 2$ & 10 & $2(20)$ & $8(80)$ & & 9 & $7(77.8)$ & $2(22.2)$ & \\
\hline PINK & & & & 1.000 & & & & 0.005 \\
\hline $0-1$ & 88 & $10(11.4)$ & 78(88.6) & & 85 & 15(17.6) & $70(82.4)$ & \\
\hline$\geq 2$ & 11 & $1(9.1)$ & 10(90.9) & & 11 & $6(54.5)$ & $5(45.5)$ & \\
\hline SUVmax & 48 & 5 & 43 & 0.005 & 46 & $9(19.6)$ & $37(80.4 \%)$ & 0.024 \\
\hline$\geq 15.4$ & 10 & $4(40.0 \%)$ & $6(60.0 \%)$ & & 9 & $5(55.6 \%)$ & $4(44.4 \%)$ & \\
\hline$<15.4$ & 38 & $1(2.6 \%)$ & $37(97.4 \%)$ & & 37 & $4(10.8 \%)$ & $33(89.2 \%)$ & \\
\hline $\begin{array}{l}\text { Disease } \\
\text { progression }\end{array}$ & $31.3 \%$ & $63.6 \%$ & $27.3 \%$ & 0.033 & $33.3 \%$ & $47.6 \%$ & $29.3 \%$ & 0.126 \\
\hline
\end{tabular}




\section{Prognostic value of plasma exoPD-L1 in ENKTCL}

The prognostic significance of plasma exoPD-L1 was evaluated in our cohort. Patients with a high pretreatment plasma exoPD-L1 level had worse 5-year PFS (35.7\% vs. $86.1 \%, P=0.007)$ and OS $(56.0 \%$ vs. $88.1 \%, P=0.012)$ than those with a low pretreatment exoPD-L1 level (Fig. 2J, 2K).

\section{Correlations between clinical features and pretreatment SPD-L1 levels}

SPD-L1 concentrations in the serum were measured in ENKTCL patients and healthy subjects. The sPD-L1 level was significantly higher in the ENKTCL patients than in the healthy individuals $(P=0.16, r=0.02)$. The optimal cutoff point for the pretreatment sPD-L1 level was 219.0 pg/ml (X-tile, Supplementary Fig. 1).

The high SPD-L1 group in our cohort was significantly associated with some clinical parameters, including an advanced stage $(P=0.0061)$, an elevated LDH level $(P<0.0001)$, B symptoms $(P=0.0058)$, a high IPI score $(P<0.0001)$ and a high PINK score $(P<0.0001)$ (Table 2$)$. The sPD-L1 level was found to be obviously higher in patients with advanced-stage disease, an elevated LDH level, extranodal sites $\geq 2$, an IPI score of 2-4 or a PINK score of 2-4 than in those with earlystage disease $(P=0.0020)$, a normal LDH level $(P=0.0008)$, extranodal sites $<2(P<0.0001)$, an IPI score of $0-1(<$ $0.0001)$ or a PINK score of $0-1(P=0.0003)$ (Fig. 3B-3G).

The correlation between plasma exoPD-L1 and SPD-L1 levels was also explored in our cohort. Interestingly, our results demonstrated that the baseline exoPD-L1 level was not associated with the SPD-L1 level in the blood $(P=0.12, r=0.45)$ (Fig. 3H).

\section{Prognostic value of SPD-L1 in the blood in ENKTCL}

In our study, the low SPD-L1 group ( $<219 \mathrm{pg} / \mathrm{mL})$ showed a favorable clinical course, with higher 5 -year OS (91.3\% vs. $55.5 \%, P=0.000)$ and 5 -year PFS rates $(68.9 \%$ vs. $34.6 \%, P=0.003)$ than the high sPD-L1 group ( $\geq 219 \mathrm{pg} / \mathrm{mL})(\mathrm{Fig} .31-$ 3J).

For stage I patients $(n=47)$, subgroup analysis demonstrated that a high sPD-L1 level was an adverse factor affecting the survival outcome. The 5-year PFS and OS rates were $71.6 \%$ and $93.9 \%$, respectively, for patients with a low level of SPD-L1 ( $219 \mathrm{pg} / \mathrm{mL}, \mathrm{n}=8)$, while the rates were $31.3 \%(P=.0022)$ and $65.6 \%(P=0.0082)$, respectively, for patients with a high pretreatment sPD-L1 level $(\geq 219 \mathrm{pg} / \mathrm{mL}, \mathrm{n}=39)$.

\section{Prognostic factors for PFS and OS}

In our study, univariate analysis demonstrated that the baseline SUVmax ( $P=0.002)$, plasma exoPD-L1 (P = 0.007), sPDL1 $(P=0.003)$ and an $L-a s p /$ peg-containing regimen $(P=0.031)$ were significant factors affecting PFS. Multivariate analysis revealed that the baseline SUVmax $(P=0.006)$ was the only significant independent factor $($ Table 3$)$. 
Table 3

Univariate and multivariate analysis of prognostic factors for survivals (by Cox regression).

\begin{tabular}{|c|c|c|c|c|c|c|c|c|}
\hline \multirow{3}{*}{$\begin{array}{l}\text { Clinical } \\
\text { factor }\end{array}$} & \multicolumn{4}{|c|}{ Progression-free survival } & \multicolumn{4}{|c|}{ Overall survival } \\
\hline & \multicolumn{2}{|c|}{ Univariate } & \multicolumn{2}{|c|}{ Multivariate } & \multicolumn{2}{|c|}{ Univariate } & \multicolumn{2}{|c|}{ Multivariate } \\
\hline & $P$ & $\mathrm{HR}(95 \% \mathrm{Cl})$ & $P$ & $\mathrm{HR}(95 \% \mathrm{Cl})$ & $P$ & HR (95\%Cl) & $P$ & HR $(95 \% \mathrm{Cl})$ \\
\hline Aged $\geq 60 y$ & 0.450 & $\begin{array}{l}1.736 \\
(0.415- \\
7.254)\end{array}$ & & & 0.433 & $\begin{array}{l}0.548 \\
(0.121- \\
2.471)\end{array}$ & & \\
\hline Gender & 0.270 & $\begin{array}{l}0.585 \\
(0.226- \\
1.516)\end{array}$ & & & 0.497 & $\begin{array}{l}0.593 \\
(0.131- \\
2.679)\end{array}$ & & \\
\hline B symptom & 0.537 & $\begin{array}{l}0.806 \\
(0.406- \\
1.599)\end{array}$ & & & 0.062 & $\begin{array}{l}0.293(0.081- \\
1.065)\end{array}$ & & \\
\hline LDH & 0.076 & $\begin{array}{l}0.467(0.201- \\
1.083)\end{array}$ & & & 0.045 & $\begin{array}{l}0.299(0.092- \\
0.974)\end{array}$ & 0.021 & $\begin{array}{l}0.038(0.002- \\
0.603)\end{array}$ \\
\hline Ki67 $\geq 60 \%$ & 0.693 & $\begin{array}{l}1.159(0.557- \\
2.411)\end{array}$ & & & 0.136 & $\begin{array}{l}2.546(0.745- \\
8.701)\end{array}$ & & \\
\hline $\begin{array}{l}\text { SUVmax } \geq \\
15.4\end{array}$ & 0.002 & $\begin{array}{l}0.205(0.068- \\
0.615)\end{array}$ & 0.006 & $\begin{array}{l}0.195(0.061- \\
0.625)\end{array}$ & 0.038 & $\begin{array}{l}0.231(0.046- \\
1.046)\end{array}$ & & \\
\hline $\mathrm{IPI}$ score $\leq 1$ & 0.146 & $\begin{array}{l}2.187 \\
(0.762- \\
6.281)\end{array}$ & & & 0.010 & $\begin{array}{l}5.570(1.511- \\
20.531)\end{array}$ & & \\
\hline $\begin{array}{l}\text { PINK score } \\
\leq 2\end{array}$ & 0.284 & $\begin{array}{l}1.776 \\
(0.621- \\
5.088)\end{array}$ & & & 0.043 & $\begin{array}{l}3.798 \\
(1.041- \\
13.856)\end{array}$ & & \\
\hline $\begin{array}{l}\text { Hemoglobin } \\
<110 \mathrm{~g} / \mathrm{L}\end{array}$ & 0.812 & $\begin{array}{l}0.886 \\
(0.326- \\
2.408)\end{array}$ & & & 0.778 & $\begin{array}{l}1.244 \\
(0.272- \\
5.697)\end{array}$ & & \\
\hline $\begin{array}{l}\text { Leukopenia } \\
<4 \times 10^{9} / \mathrm{L}\end{array}$ & 0.715 & $\begin{array}{l}0.796(0.235- \\
2.701)\end{array}$ & & & 0.477 & $\begin{array}{l}0.576 \\
(0.126- \\
2.638)\end{array}$ & & \\
\hline $\begin{array}{l}\text { Platelet < } \\
150 \times 10^{9} / \mathrm{L}\end{array}$ & 0.208 & $\begin{array}{l}3.630(0.488- \\
27.000)\end{array}$ & & & 0.632 & $\begin{array}{l}1.648 \\
(0.213- \\
12.773)\end{array}$ & & \\
\hline $\begin{array}{l}\text { ExoPD-L1 } \\
\text { (high vs. } \\
\text { low) }\end{array}$ & 0.007 & $\begin{array}{l}0.334(0.144- \\
0.777)\end{array}$ & & & 0.048 & $\begin{array}{l}0.368(0.288- \\
3.856)\end{array}$ & & \\
\hline $\begin{array}{l}\text { Serum PD- } \\
\text { L1 (high vs. } \\
\text { low) }\end{array}$ & 0.003 & $\begin{array}{l}0.337(0.157- \\
0.722)\end{array}$ & & & 0.000 & $\begin{array}{l}0.150(0.048- \\
0.472)\end{array}$ & & \\
\hline $\begin{array}{l}\text { L-asp/peg } \\
\text { containing } \\
\text { regimen }\end{array}$ & 0.031 & $\begin{array}{l}0.446 \\
(0.224- \\
0.887)\end{array}$ & & & 0.284 & $\begin{array}{l}0 . \\
550(0.184- \\
1.642)\end{array}$ & & \\
\hline $\begin{array}{l}\text { CR after } \\
\text { treatment }\end{array}$ & 0.271 & $\begin{array}{l}1.750 \\
(0.646- \\
4.746)\end{array}$ & & & 0.486 & $\begin{array}{l}1.780(0.351- \\
9.021)\end{array}$ & & \\
\hline
\end{tabular}


Some significant factors affecting OS were also identified by univariate analysis, including LDH $(P=0.045)$, plasma exoPD-L1 ( $P=0.007)$, sPD-L1 $(P=0.003)$, the IPI score $(P=0.010)$ and the PINK score $(P=0.043)$. However, multivariate analysis showed that only the LDH level $(P=0.021)$ remained a significant independent factor for OS in our study (Table 3).

\section{Discussion}

ENKTCL is a distinct subtype of lymphoma characterized by frequent EBV infection and a propensity for midline facial tissue involvement, with a higher rate of incidence in Asia than in Western countries[1]. VIPD is one of the standard treatments recommended by the National Comprehensive Cancer Network (NCCN) guidelines for the treatment of earlystage ENKTCL. In the present study, we reported the clinical efficacy of VIPD-containing regimens in ENKTCL with the largest cohort to date. In addition, we demonstrated for the first time that plasma exoPDL1 was an independent prognostic factor in ENKTCL patients. We also found that exoPD-L1 was not correlated with SPD-L1 in the blood of ENKTCL patients. The above results indicate that exoPD-L1 may contribute to immune evasion and cancer development.

VIPD is an effective and well-tolerated treatment regimen for early-stage ENKTCL patients[8, 22]. A phase II study consisting of 30 stage I/II ENKTCL patients demonstrated that $100 \%$ of patients achieved a response to VIPD chemotherapy, with 3-year PFS and OS rates of $85.19 \%$ and $86.28 \%$, respectively[22]. The response rate of VIPD in our cohort was similar to the rate found in the above study, whereas survival outcomes were even better in our study of earlystage ENKTCL patients, which reported a 5 year PFS of $53.7 \%$ and 5 year OS of $82.5 \%$. The relatively small sample size and the majority of the enrolled patients in the VIPD group being low risk may partly explain these results.

As lymphoma cells lack L-asparagine synthetase and are unable to synthesize the essential amino acid asparagine, Lasparaginase and Peg can exert anticancer effects by hydrolyzing serum asparagines in ENKTCL patients. Some Lasp/Peg based regimens such as GELOXD, SMILE and DDGP have been developed in the last decade and have been proven to be effective in ENKTCL patients[1, 7, 23]. In this study, L/P-VIPD resulted in excellent survival outcomes, with 5year PFS and 5-year OS rates of $73.6 \%$ and $88.7 \%$, respectively, consistent with the results of a previous study[8]. Compared with VIPD, the combination of L-asp/Peg could improve PFS in early-stage patients, indicating that L-asp/Peg treatment may play a key role in the prevention of recurrence.

Blockade of the PD1/PD-L1 pathway is considered a promising therapeutic approach in non-Hodgkin lymphomas, such as ENKTCL and peripheral T cell lymphoma[24]. Clinical trials have reported that PD-1 inhibitors are effective in patients with relapsed/refractory NK/T cell lymphoma and have achieved an overall response rate of 57\%-100\%[25, 26]. However, previous work predominantly focused on the expression of PD-L1 on tumor cells, and the role of exoPD-L1 has not been determined. In our study, we found that the level of PD-L1 + exosomes was significantly higher in the plasma of ENKTCL patients than in that of healthy individuals. Consistent with previous reports[27, 28], our data showed that the detection of exoPD-L1 could also differentiate ENKTCL patients from a healthy population with high sensitivity and specificity, indicating that the plasma exoPD-L1 level is a potential marker for cancer screening and diagnosis of patients with suspected malignancy.

ExoPD-L1 can mediate immune evasion in various cancers, such as melanoma and head and neck cancer[14, 28]. Our study proved hat abundant exoPD-L1 was present in the plasma of ENKTCL patients and that lymphoma cells might actively release these exosomes to create an immunosuppressive microenvironment to support cancer development. A high level of exoPD-L1 has been demonstrated to be associated with adverse clinicopathologic features, including the disease stage, in various cancers[14]. Our data demonstrated that a high level of plasma exoPD-L1 was associated with an elevated baseline SUVmax. PD-L1 expression is associated with glucose metabolism in various cancers, such as lung 
cancer and cervical cancer[29, 30]. The SUVmax in PET/CT was significantly higher in the high exoPD-L1 group and high SPD-L1 group, possibly because lymphoma cells may release PD-L1 to promote glycometabolism.

ExoPD-L1 can also serve as a biomarker for response evaluation and prognosis assessment in some cancers, such as melanoma and head and neck cancer[14,28]. Our research also showed that a high level of plasma exoPD-L1 could predict patient response and prognosis. High expression of plasma exoPD-L1 in patients was associated with a poor response and relatively poor prognosis. These studies indicate that exoPD-L1 may be a promising biomarker for tumor progression.

Previous studies have reported the clinical significance of SPD-L1 in non-Hodgkin lymphoma, such as diffuse large B cell lymphoma and NK/T cell lymphoma[24, 31, 32]. The correlation between the pretreatment SPD-L1 level and the clinical features are controversial[24,31]. Our study demonstrated that a high baseline sPD-L1 level was correlated with some adverse clinical characteristics, including an advanced stage, an elevated LDH level, B symptoms, a high IPI score and a high PINK score.

The predictive value of pretreatment SPD-L1 has been assessed in previous studies[24, 31]. Patients with a high concentration ( $>3.23 \mathrm{ng} / \mathrm{L}, \mathrm{n}=34$ ) of SPD-L1 were found to have significantly worse PFS (3-year PFS 85.0 vs. $25.6 \%, \mathrm{P}<$ $0.001)$ and OS (3-year OS 51.7 vs. $91.3 \%, P<0.001)$ than those with a low concentration $(\leq 3.23 \mathrm{ng} / \mathrm{L}, \mathrm{n}=63)[31]$. Consistent with this study, our research found that a high pretreatment level of SPD-L1 was an important prognostic factor for PFS and OS, indicating that the baseline SPD-L1 level is a potential prognostic biomarker in ENKTCL patients.

The correlation between exoPD-L1 and SPD-L1 levels in the blood was investigated in a previous study[14]. In this study, no correlation between the exoPD-L1 and SPD-L1 levels in the plasma was observed in the head and neck cancer patients. Although both plasma exoPD-L1 and SPD-L1 were associated with a relatively poor prognosis in our study, there was no relationship between these two variables in our patients. The following reasons may explain the above results: 1) PD-L1 on exomes was more stable than SPD-L1 in the plasma; 2) the cell sources of exoPD-L1 and SPD-L1 might be different, and 3) the production and secretion of SPD-L1 by cells was independent of the process of exosome biogenesis.

Several other risk factors were also identified in our study, including the LDH level, baseline SUVmax, IPI and PINK. ${ }^{18} \mathrm{~F}$ FDG PET/CT is a standard imaging technology used to stage disease, evaluate responses and monitor for relapse in lymphoma patients[33]. The baseline SUVmax in PET/CT is an important prognostic factor in lymphoma[34, 35]. Our results support previous observations that the baseline SUVmax correlates with prognosis in ENKTCL[35]. The PINK score represents a new model used to predict outcomes in ENKTCL patients treated with non-anthracycline-based therapies, and this model was confirmed in subsequent studies[7, 36]. Our research assessed the impact of the PINK on prognosis and found that a high PINK score was associated with a worse outcome.

In conclusion, our results revealed that VIPD-containing chemotherapy was an effective regimen for patients with nasaltype ENKTCL and that abundant PD-L1 was enriched on exosomes derived from patient plasma. In addition, high levels of circulating exoPD-L1 and SPD-L1 were important predictors of adverse survival outcomes, and they could serve as valuable diagnostic and prognostic biomarkers for ENKTCL patients.

\section{Abbreviations}

ENKTCL: Extranodal NK/T cell lymphoma; PFS: progression-free survival; OS: overall survival; EBV: Epstein-Barr virus; Lasp: L-asparaginase; PD-1: programmed death protein 1; PD-L1: programmed death ligand 1; ExoPD-L1: Exosomal PD-L1; SPD-L1: Soluble PD-L1; VIPD: etoposide, ifosfamide, cisplatin and dexamethasone. EVs: Extracellular vesicles; TEM: Transmission electron microscopy (TEM); ELISA: Enzyme linked immunosorbent assay; LDH: Lactate dehydrogenase; IPI: International Prognostic Index; PINK: Prognostic Index for NK/T cell lymphoma.

Page $12 / 20$ 


\section{Declarations}

\section{Acknowledgments}

We would like to thank Fei Wu and Ji Liang of Fudan University Shanghai Cancer Center for their technical assistance and data.

\section{Authors' contributions}

JW Li, P Wei and Y Guo were involved in the study design, data collection, and writing of the manuscript; JW Li, D Shi, BH Yu and YF Su and XQ-Li were involved in data collection and data interpretation. This paper was reviewed and approved by all authors, and the corresponding author Prof. Zhou had the final responsibility over the decision to submit for publication.

\section{Funding}

This work was supported by the National Natural Science Foundation of China (No. 81470353, 81870155, 81700195), Innovation Group Project of Shanghai Municipal Health Comission (2019CXJQ03), Shanghai Science and technology development fund (19MC1911000), and Shanghai Municipal Key Clinical Specialty (shslczdzk01301).

\section{Availability of data and materials}

All data in this study are included in this publication and related data files.

\section{Ethics approval and consent to participate}

All experiments and data generation were in accordance with the ethics standards of the relevant national and international rules and regulations (GCP, Declaration of Helsinki). This study was approved by the Ethics Committee of Fudan University Shanghai Cancer Center, and each participant signed an informed consent form before enrollment in this study.

\section{Consent for publication}

Not applicable.

\section{Competing interests}

The authors have no competing interests to declare in this work.

\section{References}

1. Yamaguchi M, Suzuki R and Oguchi M. Advances in the treatment of extranodal NK/T-cell lymphoma, nasal type. Blood 2018; 131: 2528-2540. 
2. Wang L, Xia ZJ, Huang HQ, Lu Y and Zhang YJ. Cyclophosphamide, doxorubicin, vincristine, and prednisone (CHOP) in the treatment of stage IE/IIE extranodal natural killer/T cell lymphoma, nasal type: 13-year follow-up in 135 patients. Int J Hematol 2012; 96: 617-623.

3. Kim BS, Kim TY, Kim CW, Kim JY, Heo DS, Bang YJ and Kim NK. Therapeutic outcome of extranodal NK/T-cell lymphoma initially treated with chemotherapy-result of chemotherapy in NK/T-cell lymphoma. Acta Oncol 2003; 42: 779-783.

4. Zhang L, Jiang M, Xie L, Zhang H, Jiang Y, Yang QP, Liu WP, Zhang WY, Zhuo HY, Li P, Chen NY, Zhao S, Wang F and Zou LQ. Five-year analysis from phase 2 trial of "sandwich" chemoradiotherapy in newly diagnosed, stage IE to IIE, nasal type, extranodal natural killer/T-cell lymphoma. Cancer Med 2016; 5: 33-40.

5. Tsai HJ, Lin SF, Chen CC, Chen TY, Su WC, Hwang WL, Lin JC, Chiou TJ, Kao WY, Chiu CF, Chang YF, Chang JS, Chang $\mathrm{MC}$ and Su IJ. Long-term results of a phase II trial with frontline concurrent chemoradiotherapy followed by consolidation chemotherapy for localized nasal natural killer/T-cell lymphoma. Eur J Haematol 2015; 94: 130-137.

6. Kim SJ, Yang DH, Kim JS, Kwak JY, Eom HS, Hong DS, Won JH, Lee JH, Yoon DH, Cho J, Nam TK, Lee SW, Ahn YC, Suh $\mathrm{C}$ and Kim WS. Concurrent chemoradiotherapy followed by L-asparaginase-containing chemotherapy, VIDL, for localized nasal extranodal NK/T cell lymphoma: CISL08-01 phase II study. Ann Hematol 2014; 93: 1895-1901.

7. Li JW, Li YJ, Zhong MZ, Liu XL, Li J, Li KL, Liu XY, Zhou F, OuYang Z, Sun ZY, Huang LJ, He JQ, Zhou H and Yi PY. Efficacy and tolerance of GELOXD/P-GEMOXD in newly diagnosed nasal-type extranodal NK/T-cell lymphoma: A multicenter retrospective study. Eur J Haematol 2018; 100: 247-256.

8. Dong LH, Zhang LJ, Wang WJ, Lei W, Sun X, Du JW, Gao X, Li GP and Li YF. Sequential DICE combined with Iasparaginase chemotherapy followed by involved field radiation in newly diagnosed, stage IE to IIE, nasal and extranodal NK/T-cell lymphoma. Leuk Lymphoma 2016; 57: 1600-1606.

9. Rutherford SC, Fachel AA, Li S, Sawh S, Muley A, Ishii J, Saxena A, Dominguez PM, Caldas Lopes E, Agirre X, Chambwe N, Correa F, Jiang Y, Richards KL, Betel D and Shaknovich R. Extracellular vesicles in DLBCL provide abundant clues to aberrant transcriptional programming and genomic alterations. Blood 2018; 132: e13-e23.

10. Feng YH ZM, Zeng S,et al. Exosome-derived miRNAs as predictive biomarkers for diffuse large B-cell lymphoma chemotherapy resistance. Epigenomics 2018;

11. Li J, Tian T and Zhou X. The role of exosomal shuttle RNA (esRNA) in lymphoma. Crit Rev Oncol Hematol 2019; 137 : 27-34.

12. Kataoka K, Miyoshi H, Sakata S, Dobashi A, Couronne L, Kogure Y, Sato Y, Nishida K, Gion Y, Shiraishi Y, Tanaka H, Chiba K, Watatani Y, Kakiuchi N, Shiozawa Y, Yoshizato T, Yoshida K, Makishima H, Sanada M, Onozawa M, Teshima T, Yoshiki Y, Ishida T, Suzuki K, Shimada K, Tomita A, Kato M, Ota Y, Izutsu K, Demachi-Okamura A, Akatsuka Y, Miyano S, Yoshino T, Gaulard P, Hermine O, Takeuchi K, Ohshima K and Ogawa S. Frequent structural variations involving programmed death ligands in Epstein-Barr virus-associated lymphomas. Leukemia 2019; 33: 1687-1699.

13. Chen G, Huang AC, Zhang W, Zhang G, Wu M, Xu W, Yu ZL, Yang JG, Wang BK, Sun HH, Xia HF, Man QW, Zhong WQ, Antelo LF, Wu B, Xiong XP, Liu XM, Guan L, Li T, Liu SJ, Yang RF, Lu YT, Dong LY, McGettigan S, Somasundaram R, Radhakrishnan R, Mills G, Lu YL, Kim J, Chen YHH, Dong HD, Zhao YF, Karakousis GC, Mitchell TC, Schuchter LM, Herlyn M, Wherry EJ, Xu XW and Guo W. Exosomal PD-L1 contributes to immunosuppression and is associated with anti-PD-1 response. Nature 2018; 560: 382-+.

14. Theodoraki MN, Yerneni SS, Hoffmann TK, Gooding WE and Whiteside TL. Clinical Significance of PD-L1(+) Exosomes in Plasma of Head and Neck Cancer Patients. Clin Cancer Res 2018; 24: 896-905.

15. Yang Y, Li CW, Chan LC, Wei Y, Hsu JM, Xia W, Cha JH, Hou J, Hsu JL, Sun L and Hung MC. Exosomal PD-L1 harbors active defense function to suppress T cell killing of breast cancer cells and promote tumor growth. Cell Res 2018; 28: 862-864. 
16. Poggio M, Hu T, Pai CC, Chu B, Belair CD, Chang A, Montabana E, Lang UE, Fu Q, Fong L and Blelloch R. Suppression of Exosomal PD-L1 Induces Systemic Anti-tumor Immunity and Memory. Cell 2019; 177: 414-427 e413.

17. Cheson BD, Pfistner B, Juweid ME, Gascoyne RD, Specht L, Horning SJ, Coiffier B, Fisher RI, Hagenbeek A, Zucca E, Rosen ST, Stroobants S, Lister TA, Hoppe RT, Dreyling M, Tobinai K, Vose JM, Connors JM, Federico M, Diehl V and International Harmonization Project on L. Revised response criteria for malignant lymphoma. J Clin Oncol 2007; 25: 579-586.

18. Thery C, Amigorena S, Raposo G and Clayton A. Isolation and characterization of exosomes from cell culture supernatants and biological fluids. Curr Protoc Cell Biol 2006; Chapter 3: Unit 322.

19. Tian Y, Ma L, Gong M, Su G, Zhu S, Zhang W, Wang S, Li Z, Chen C, Li L, Wu L and Yan X. Protein Profiling and Sizing of Extracellular Vesicles from Colorectal Cancer Patients via Flow Cytometry. ACS Nano 2018; 12: 671-680.

20. Wilson DH, Rissin DM, Kan CW, Fournier DR, Piech T, Campbell TG, Meyer RE, Fishburn MW, Cabrera C, Patel PP, Frew E, Chen Y, Chang L, Ferrell EP, von Einem V, McGuigan W, Reinhardt M, Sayer H, Vielsack C and Duffy DC. The Simoa HD-1 Analyzer: A Novel Fully Automated Digital Immunoassay Analyzer with Single-Molecule Sensitivity and Multiplexing. J Lab Autom 2016; 21: 533-547.

21. Andreu Z and Yanez-Mo M. Tetraspanins in extracellular vesicle formation and function. Front Immunol 2014; 5: 442.

22. Kim SJ, Kim K, Kim BS, Kim CY, Suh C, Huh J, Lee SW, Kim JS, Cho J, Lee GW, Kang KM, Eom HS, Pyo HR, Ahn YC, Ko $\mathrm{YH}$ and Kim WS. Phase II trial of concurrent radiation and weekly cisplatin followed by VIPD chemotherapy in newly diagnosed, stage IE to IIE, nasal, extranodal NK/T-Cell Lymphoma: Consortium for Improving Survival of Lymphoma study. J Clin Oncol 2009; 27: 6027-6032.

23. Li X, Cui Y, Sun Z, Zhang L, Li L, Wang X, Wu J, Fu X, Ma W, Zhang X, Chang Y, Nan F, Li W, Su L, Wang J, Xue H and Zhang M. DDGP versus SMILE in Newly Diagnosed Advanced Natural Killer/T-Cell Lymphoma: A Randomized Controlled, Multicenter, Open-label Study in China. Clin Cancer Res 2016; 22: 5223-5228.

24. Nagato T, Ohkuri T, Ohara K, Hirata Y, Kishibe K, Komabayashi Y, Ueda S, Takahara M, Kumai T, Ishibashi K, Kosaka A, Aoki N, Oikawa K, Uno Y, Akiyama N, Sado M, Takei H, Celis E, Harabuchi Y and Kobayashi H. Programmed deathligand 1 and its soluble form are highly expressed in nasal natural killer/T-cell lymphoma: a potential rationale for immunotherapy. Cancer Immunol Immunother 2017; 66: 877-890.

25. Kwong YL, Chan TSY, Tan D, Kim SJ, Poon LM, Mow B, Khong PL, Loong F, Au-Yeung R, Iqbal J, Phipps C and Tse E. PD1 blockade with pembrolizumab is highly effective in relapsed or refractory NK/T-cell lymphoma failing Iasparaginase. Blood 2017; 129: 2437-2442.

26. Li X, Cheng Y, Zhang M, Yan J, Li L, Fu X, Zhang X, Chang Y, Sun Z, Yu H, Zhang L, Wang X, Wu J, Li Z, Nan F, Tian L, $\mathrm{Li} W$ and Young KH. Activity of pembrolizumab in relapsed/refractory NK/T-cell lymphoma. J Hematol Oncol 2018; 11: 15.

27. Pang Y, Shi J, Yang X, Wang C, Sun Z and Xiao R. Personalized detection of circling exosomal PD-L1 based on Fe304@TiO2 isolation and SERS immunoassay. Biosens Bioelectron 2020; 148: 111800.

28. Chen G, Huang AC, Zhang W, Zhang G, Wu M, Xu W, Yu Z, Yang J, Wang B, Sun H, Xia H, Man Q, Zhong W, Antelo LF, Wu B, Xiong X, Liu X, Guan L, Li T, Liu S, Yang R, Lu Y, Dong L, McGettigan S, Somasundaram R, Radhakrishnan R, Mills G, Lu Y, Kim J, Chen YH, Dong H, Zhao Y, Karakousis GC, Mitchell TC, Schuchter LM, Herlyn M, Wherry EJ, Xu X and Guo W. Exosomal PD-L1 contributes to immunosuppression and is associated with anti-PD-1 response. Nature 2018; 560: 382-386.

29. Kaira K, Shimizu K, Kitahara S, Yajima T, Atsumi J, Kosaka T, Ohtaki Y, Higuchi T, Oyama T, Asao T and Mogi A. 2Deoxy-2-[fluorine-18] fluoro-d-glucose uptake on positron emission tomography is associated with programmed death ligand-1 expression in patients with pulmonary adenocarcinoma. Eur J Cancer 2018; 101: 181-190.

Page $15 / 20$ 
30. Wang S, Li J, Xie J, Liu F, Duan Y, Wu Y, Huang S, He X, Wang Z and Wu X. Programmed death ligand 1 promotes lymph node metastasis and glucose metabolism in cervical cancer by activating integrin beta4/SNAI1/SIRT3 signaling pathway. Oncogene 2018; 37: 4164-4180.

31. Wang H, Wang L, Liu WJ, Xia ZJ, Huang HQ, Jiang WQ, Li ZM and Lu Y. High post-treatment serum levels of soluble programmed cell death ligand 1 predict early relapse and poor prognosis in extranodal NK/T cell lymphoma patients. Oncotarget 2016; 7: 33035-33045.

32. Rossille D, Gressier M, Damotte D, Maucort-Boulch D, Pangault C, Semana G, Le Gouill S, Haioun C, Tarte K, Lamy T, Milpied N, Fest T, Groupe Ouest-Est des Leucemies et Autres Maladies du S and Groupe Ouest-Est des Leucemies et Autres Maladies du S. High level of soluble programmed cell death ligand 1 in blood impacts overall survival in aggressive diffuse large B-Cell lymphoma: results from a French multicenter clinical trial. Leukemia 2014; 28 : 23672375.

33. Trotman J, Barrington SF, Belada D, Meignan M, MacEwan R, Owen C, Ptacnik V, Rosta A, Fingerle-Rowson GR, Zhu J, Nielsen T, Sahin D, Hiddemann W, Marcus RE, Davies A and study PETiftG. Prognostic value of end-of-induction PET response after first-line immunochemotherapy for follicular lymphoma (GALLIUM): secondary analysis of a randomised, phase 3 trial. Lancet Oncol 2018; 19: 1530-1542.

34. Cheson BD. PET/CT in Lymphoma: Current Overview and Future Directions. Semin Nucl Med 2018; 48: 76-81.

35. Pak K, Kim BS, Kim K, Kim IJ, Jun S, Jeong YJ, Shim HK, Kim SD and Cho KS. Prognostic significance of standardized uptake value on F18-FDG PET/CT in patients with extranodal nasal type NK/T cell lymphoma: A multicenter, retrospective analysis. Am J Otolaryngol 2018; 39: 1-5.

36. Chen SY, Yang Y, Qi SN, Wang Y, Hu C, He X, Zhang LL, Wu G, Qu BL, Qian LT, Hou XR, Zhang FQ, Qiao XY, Wang H, Li GF, Zhang YJ, Zhu Y, Cao JZ, Lan SM, Wu JX, Wu T, Zhu SY, Shi M, Xu LM, Yuan ZY, Yahalom J, Tsang R, Song YQ, Zhu J, Su H and Li YX. Validation of nomogram-revised risk index and comparison with other models for extranodal nasal-type NK/T-cell lymphoma in the modern chemotherapy era: indication for prognostication and clinical decision-making. Leukemia 2020;

\section{Figures}


Figue 1

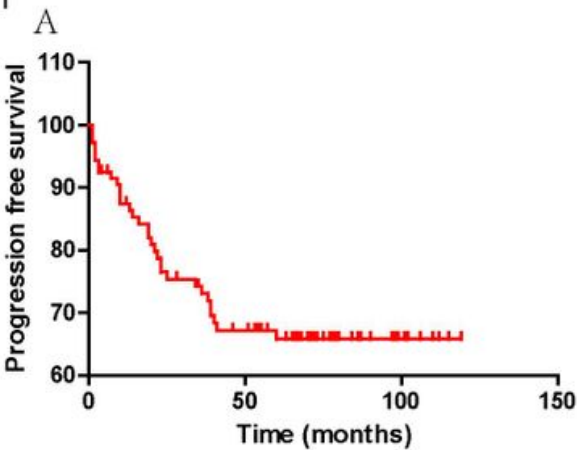

$\mathrm{D}$

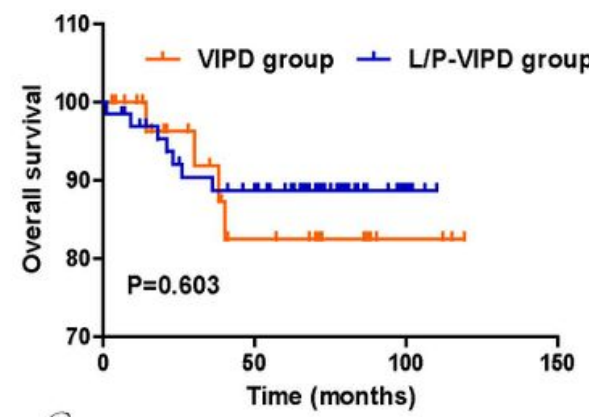

G

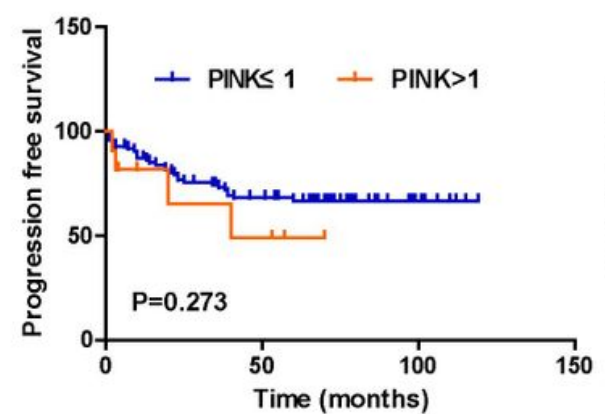

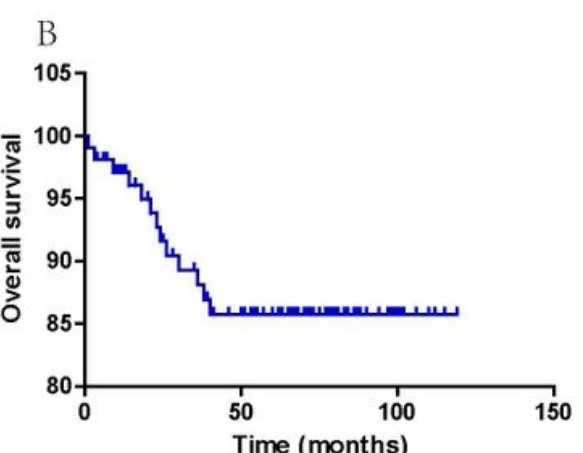

$\mathrm{E}$

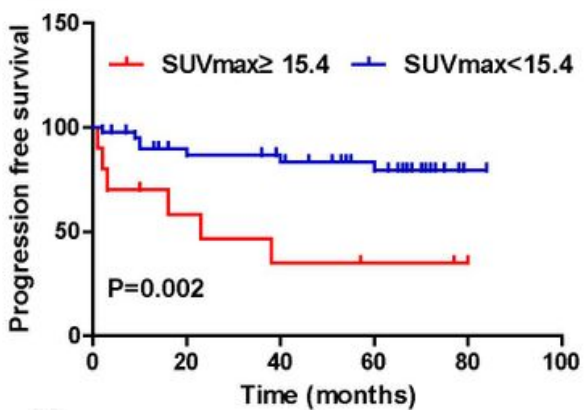

$\mathrm{H}$
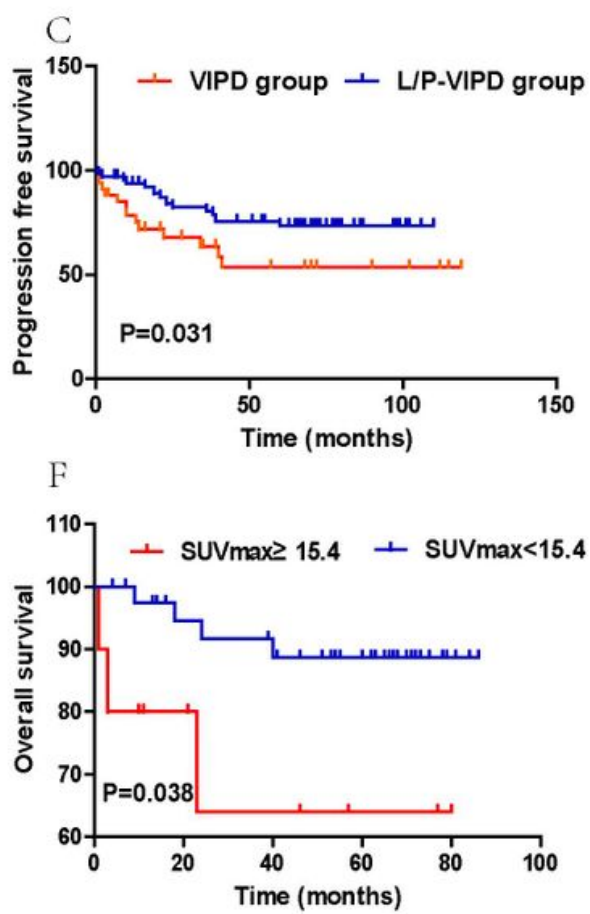

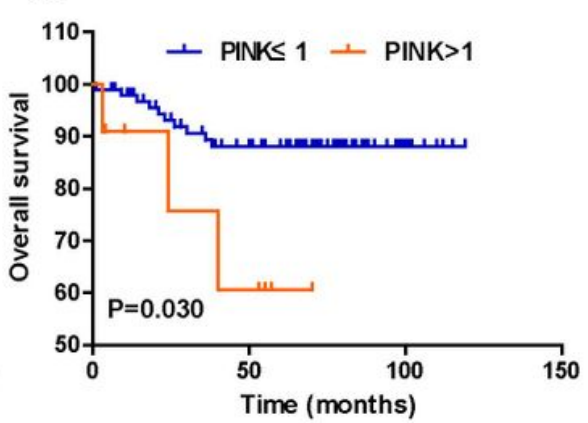

Figure 1

$A, B$, Progression-free survival (PFS) and overall survival (OS) for all patients $(A, B)$. C and $D$, Comparison of progressionfree survival (PFS) (C) and overall survival (OS) (D) between VIPD group and L/P-VIPD group for early stage ENKTCL patients. E and F, Impact of pretreatment SUVmax on the PFS (E) and OS (F) for ENKTCL patients. G and H, Significant impact of PINK on progression-free survival (PFS) (E) and overall survival (OS). 

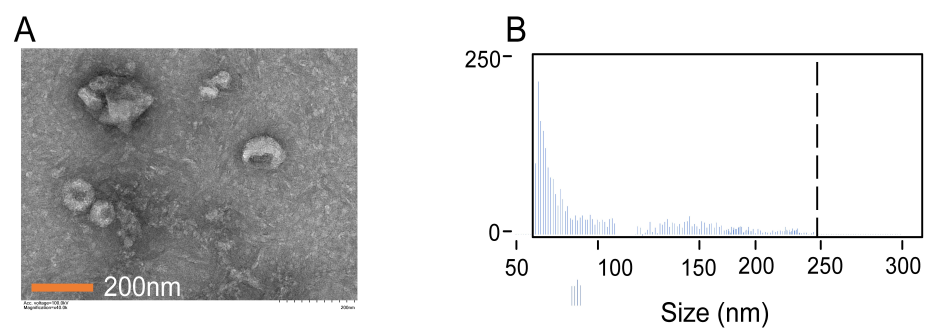

C

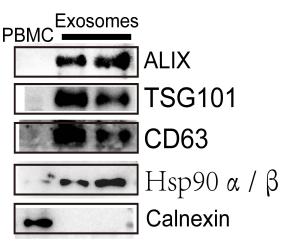

D
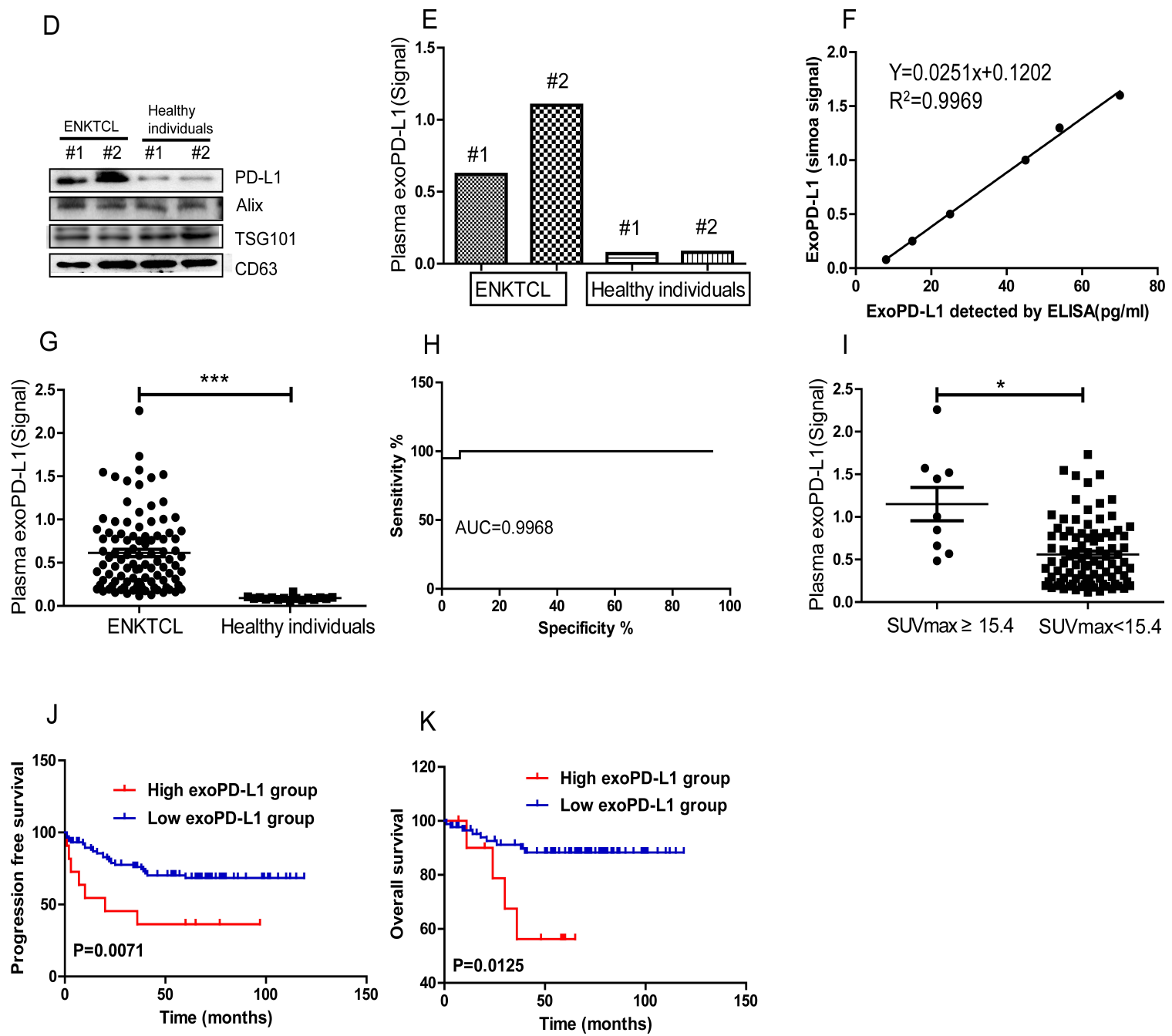

\section{Figure 2}

A-C. Characterization of isolated exosomes by transmission electron microscopy (TEM) (A), size distribution (B) and western blots (C). D-E. The plasma exoPD-L1 level of ENKTCL patients and healthy individuals analyzed by western blots and simoa. F. Linear relationship between the simoa signal and the exoPD-L1 concentration detected by ELISA G. Plasma exoPD-L1 level measured by Simoa in 16 healthy subjects and 99 patients with ENKTCL at diagnosis. H. ROC analysis to evaluate the diagnostic power to detect NSCLC cases $(n=99)$ from the healthy controls $(n=16)$. I. The exoPD-L1 level are significantly higher in patients with high SUVmax level $(\geq 15.4)$ than those with lower SUVmax level at diagnosis. J-K. Kaplan-Meier estimates of PFS (J) and OS (K) considering the cutoff point for exoPD-L1 at 1.2 (simoa signal). 
Figure 3

A

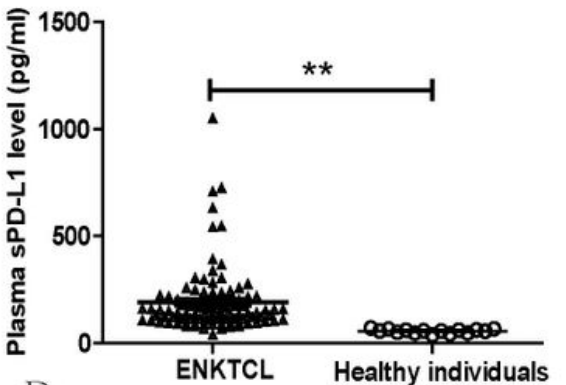

$\mathrm{D}$

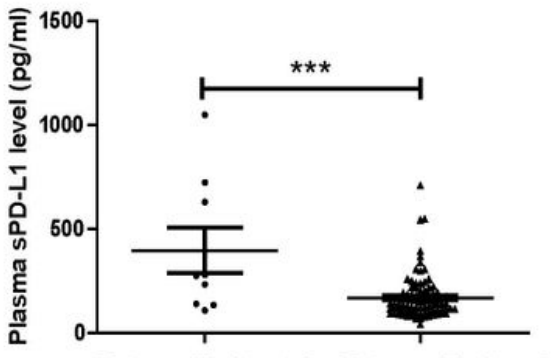

Extranodal sites $\geq 2$ Extranodal sites $<2$
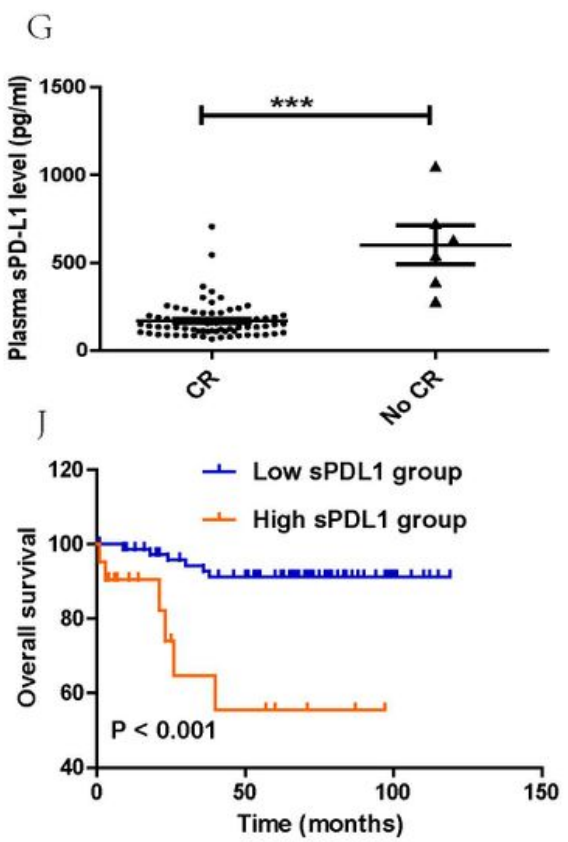

$\mathrm{B}$

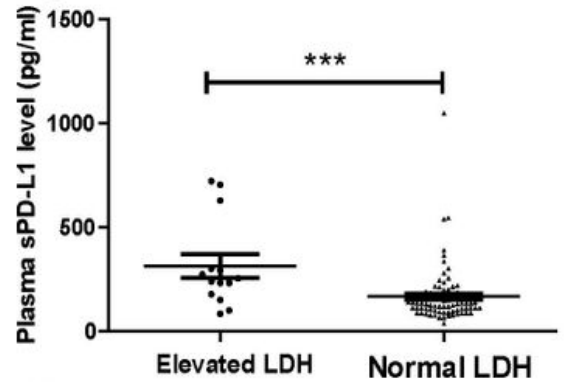

$\mathrm{E}$
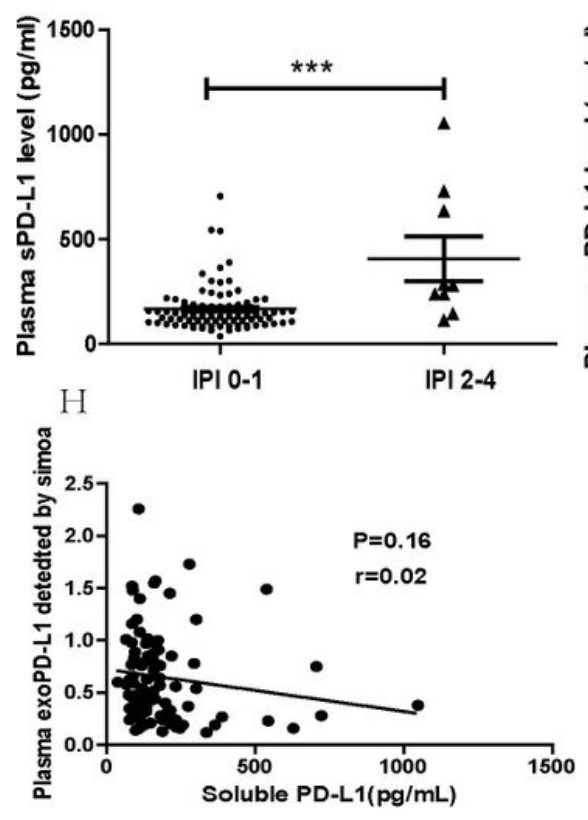

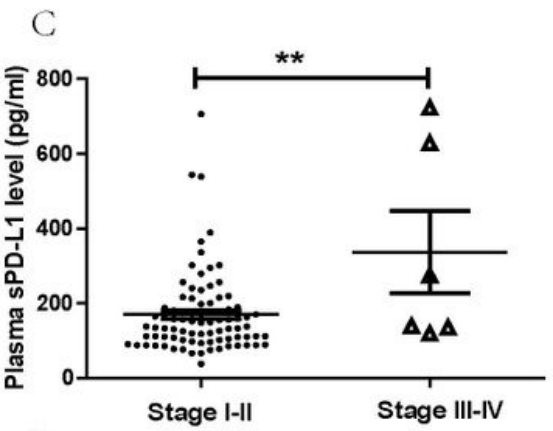

F
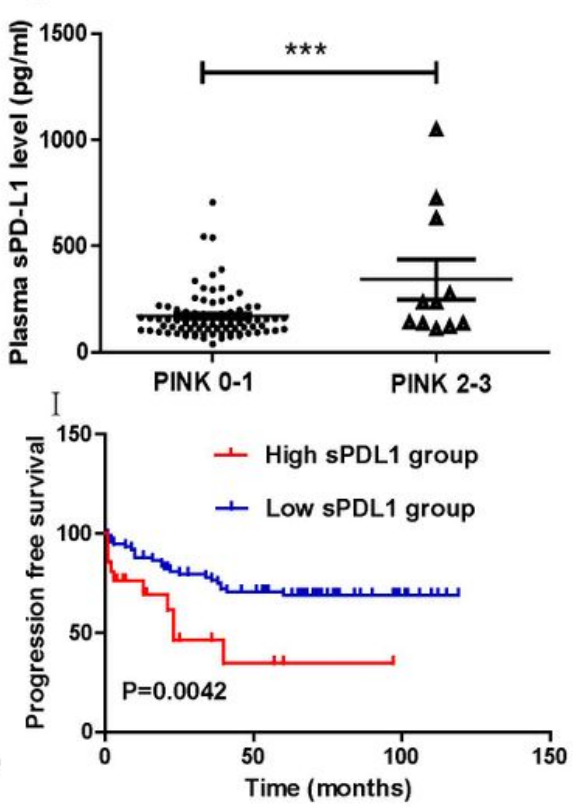

\section{Figure 3}

A. circulating SPD-L1 protein measurement in 16 healthy subjects and for the 96 patients with ENKTCL collected at diagnosis. B-G. The SPD-L1 level are significantly higher in patients with elevated LDH level (B), advanced stage disease (C), extranodal sites $\geq 2$ (D), IPI $\geq 2(E), P I N K>1$ (F) and CR status (G) in ENKTCL. * $P<0.05 ; \star \star, P<0.001, * \star \star, P<0.0001$. H. No correlation between the exoPD-L1 in patients' plasma and the soluble PD-L1 level; Spearman's correlation at $P=0.16$, $r=0.02$. I-J. Kaplan-Meier estimates of PFS (I) and OS (J) considering the cutoff point for SPD-L1 at 219.0 pg/ml.

\section{Supplementary Files}

This is a list of supplementary files associated with this preprint. Click to download.

- Supplementalmaterials.docx 
- Supplementalmaterials.docx

Page 20/20 